\title{
Some Observations on the Influence of the Hydrogen-ion Concentration on the Pain Reaction in the Administration of Sodium Hydnocarpate Solutions by Subcutaneous Infiltration.
}

\author{
J. T. JACKSON.
}

T $\mathrm{N}$ the administration of sodium hydnocarpate products by the subcutaneous infiltration method commonly employed in the treatment of leprosy, it has been remarked by various users, that the amount of pain experienced by the patient following the injection, varies with different batches of the same product.

The writer thought that perhaps one factor influencing the pain reaction might probably be due to variations in the hydrogen-ion concentration of the solutions injected. Mention of this suggestion is referred to by Dr. Cochrane ${ }^{2}$ in his paper on the use of "Alepol."

Dr. Cochrane was good enough to refer this suggestion to Dr. T. A. Henry, of Messrs. Burroughs, Wellcome and Co.'s research laboratories, and Dr. Henry very kindly supplied the author with samples of the sodium salts of a fraction of the fatty acids from hydnocarpus oil. $\mathrm{He}$ also had carried out in his laboratories the determination of the hydrogen-ion concentrations employed in this investigation. The samples of sodium hydnocarpate used were tested on guinea pigs before being sent to India.

This paper is an account of the experimental work carried out by the author on patients at the Bankura Leprosy Home in Bengal, and the observations and conclusions arising therefrom.

Pain Reaction.

It is realised that there are many components affecting the pain following the administration of aqueous solutions of sodium hydnocarpate by the subcutaneous infiltration method. The pain reaction varies with the temperament of the patient, his general health and physique, the extent and degree of anæsthesia over areas where injections are made, the psychological factor which exists when treating a number of patients together, the climatic conditions and also the technique and general personal equation of the experimentalist.

In order to keep these varying factors uniform, as 
constant and as small as possible, the experimental details outlined below were adopted. The personal equation was kept as constant as possible throughout by the writer himself carrying out all the experimental details such as the preparation of the solutions, the injection of patients and the taking of observations of signs and symptoms for the record of the pain reaction resulting from each injection.

For the purpose of collating all the observations made, a mathematical expression for the pain reaction has been originated as explained below. It has been named the "Pain Factor," and is denoted throughout by the letters "P.F." This has enabled comparative results to be made and has a purely relative value.

\section{EXPERIMENTAL.}

\section{Sodium Hydnocarpate Fractions and Solutions.}

Two separate batches of sodium hydnocarpate were supplied by Dr. Henry. The first batch of five samples $(A, B, C, D, E)$ were supplied from one fraction " $\mathrm{X}$ " of the fatty acids from hydnocarpus oil and were tested at the Leprosy Home from August to October, of 1929. A further batch of samples $(F, G, H, J)$ were examined in June, of 1930 . This batch was prepared separately from the first batch and has been treated as such.

The solutions used throughout for injection were of the same strength as that generally employed in routine work, i.e., 3 per cent. aqueous sodium hydnocarpate containing 0.5 per cent. of carbolic acid. The solutions were accurately prepared and sterilised in rubber capsuled bottles. The sodium hydnocarpate was dissolved in the dilute carbolic acid, made up to the correct volume and sterilised. The records below were made of the solutions.

Some of the samples tended to cake up and form a colloidal mass before dissolving whilst others were more of a powder and dissolved readily.

It was found that all the solutions kept well over the period through which they were employed.

Sample A.-A dry powder which caked up before dissolving. It formed a dark yellow solution when hot and on cooling.

Sample B.-More readily soluble than " C." It formed a dark yellow solution when hot which became pale yellow when cold.

Sample C.-This sample caked up and formed a cloudy solution in the cold which clarified on heating; 24 hours 


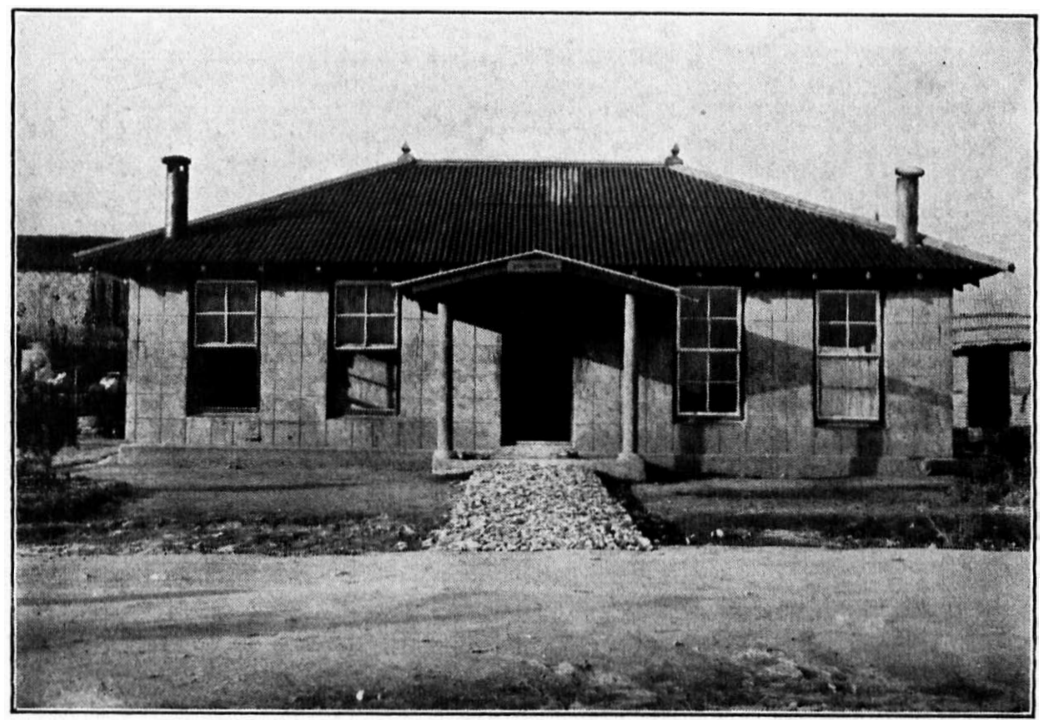

By kind permission of the Mission to Lepers.

Onf of the Men's Cottages in the Soonchun Leprosy Settlement. It consists of a Hai.l, Four Bedrooms, a Kitchen, and an Attic.

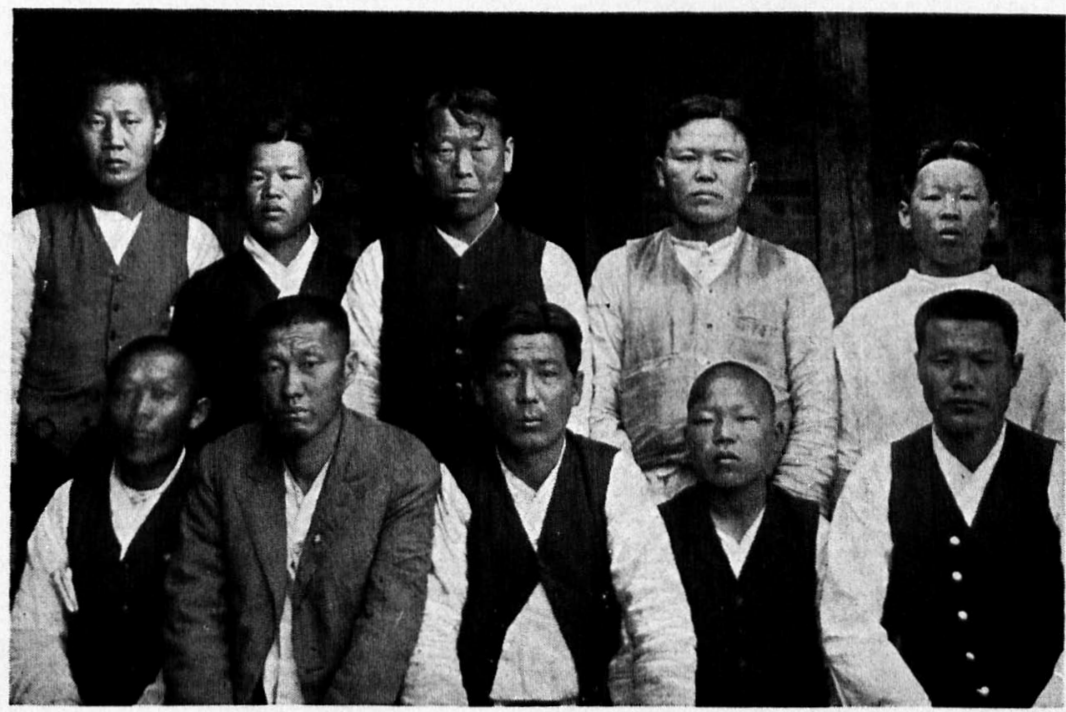

By kind permission of the Mission to Lepers.

Ten Typical Cases on the Eve of their Discharge from the Colony. 
MAP SHOWING RELATIVE

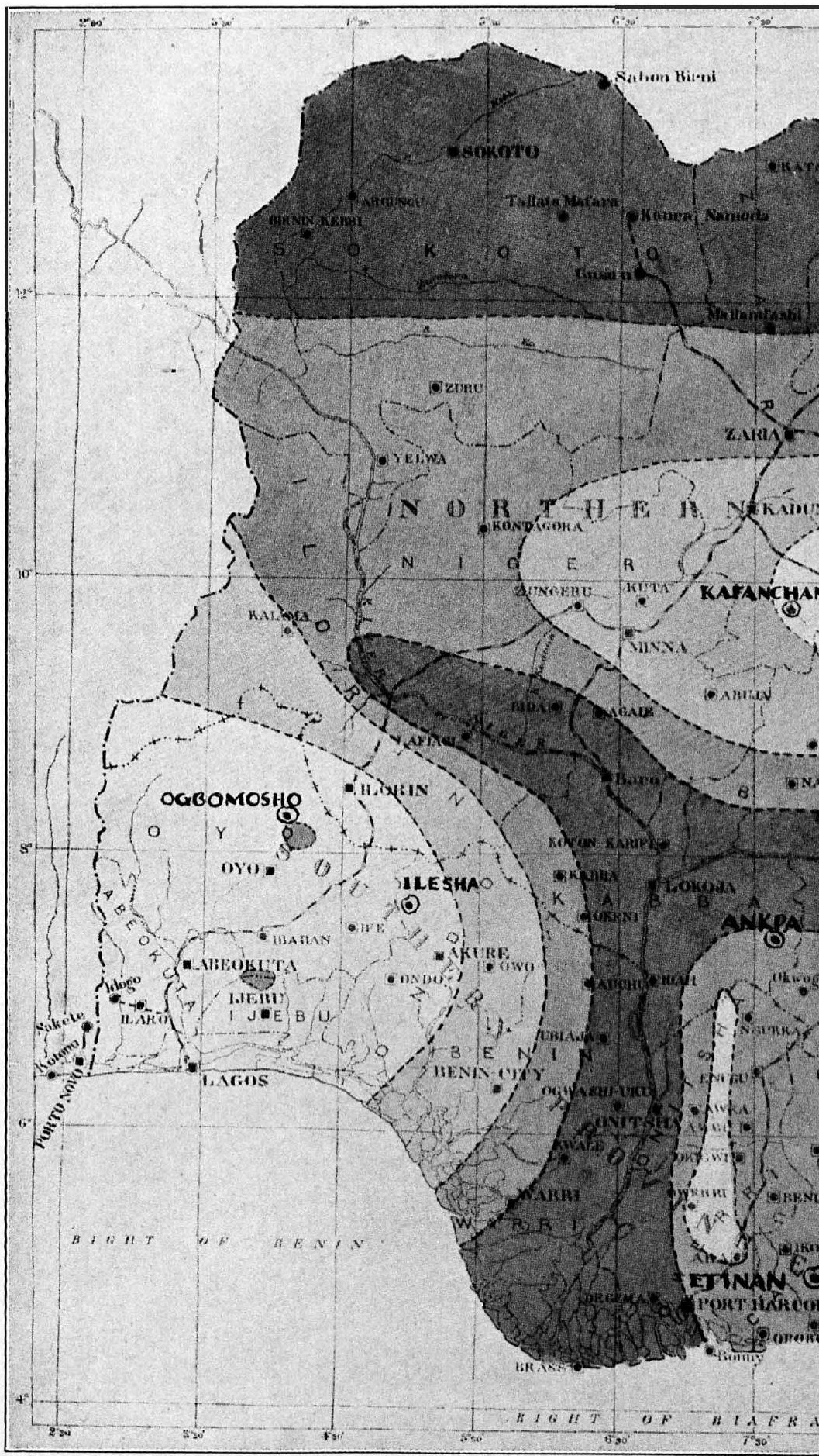




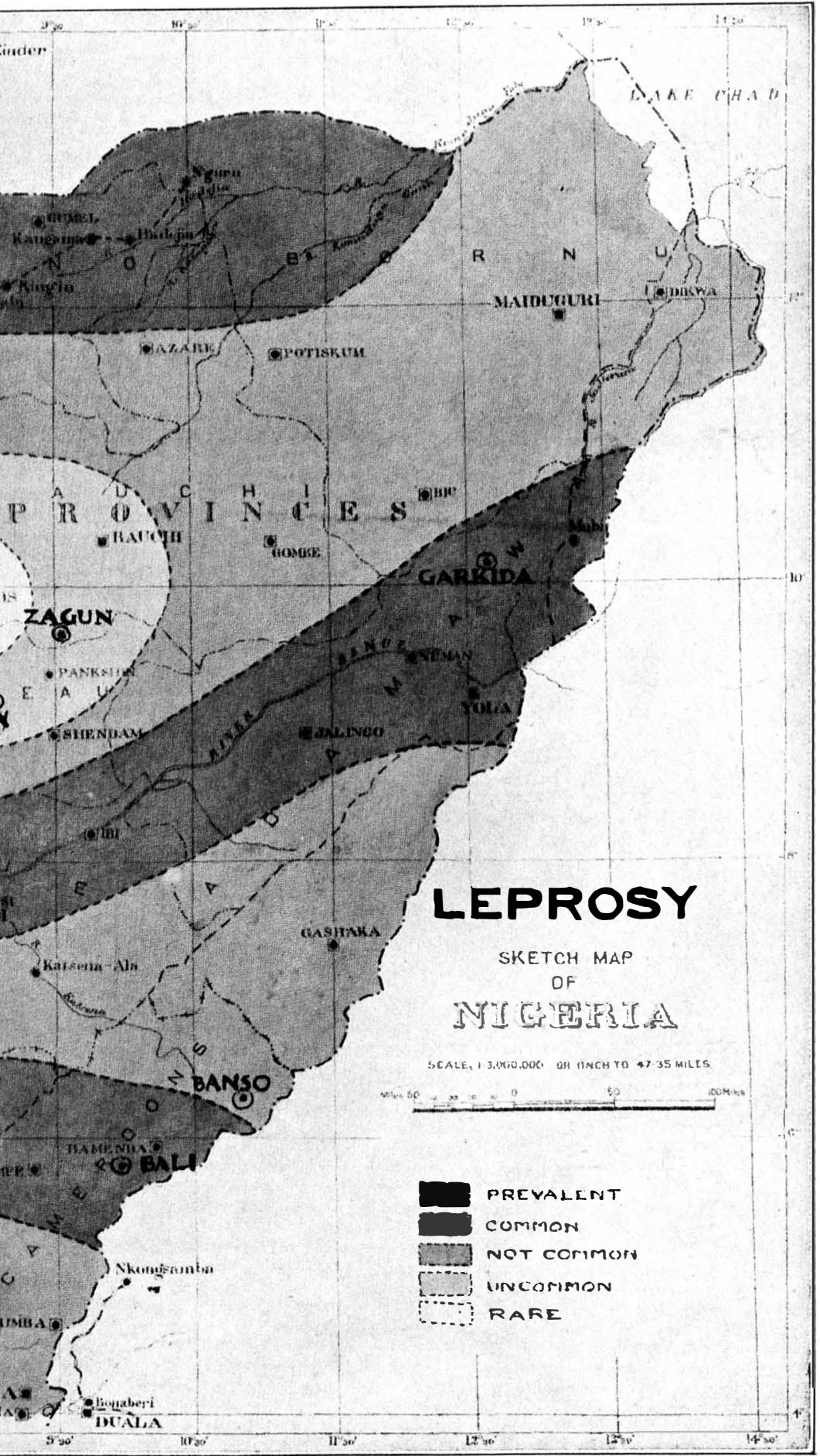

(By perinission.) 


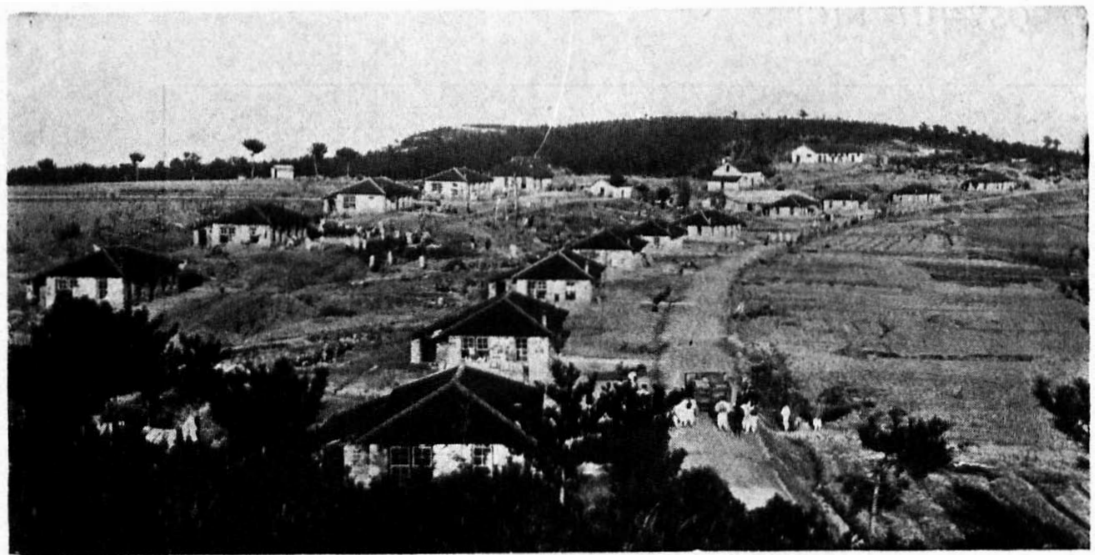

Bykind permission of the Mission to Lepers.

General View of the Men's Side of the Soonchun Leprosy Colony.

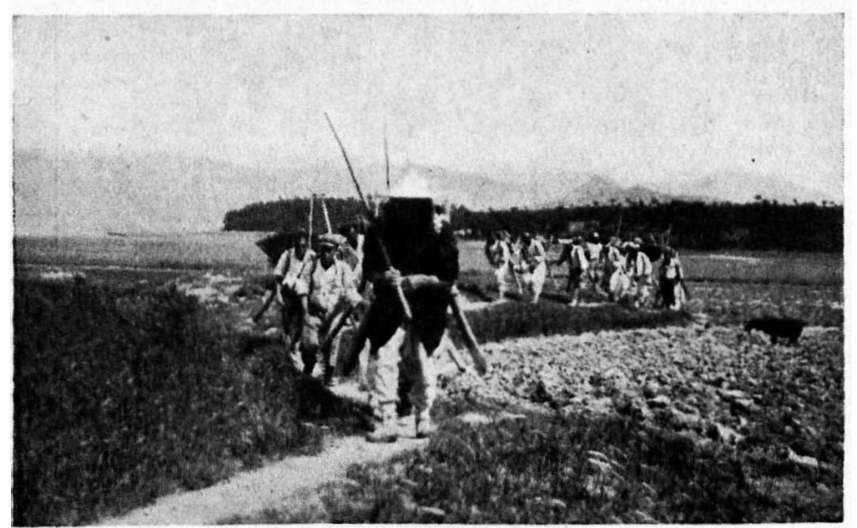

By kind permission of the Mission to Lepers.

Patients Bringing Stone from the Quarrirs in the Colony.

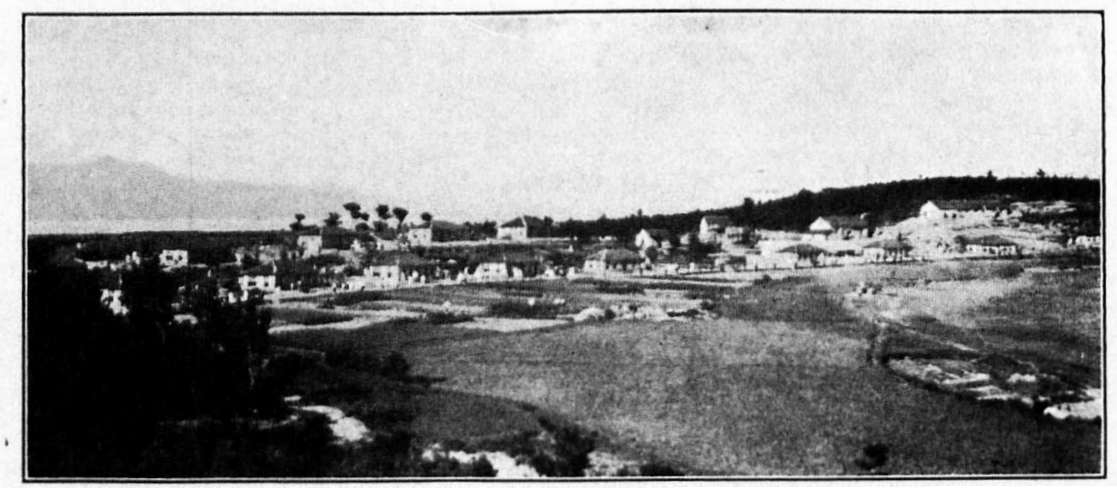

By kind permission of the Mission to Lepers.

A Partial View of the Women's Section of the Colony. 
after sterilising, the solution was paler in colour and a slight precipitation (probably of fatty acid) took place.

Sample D.-A finer powder but not so readily soluble as " B," forming a dark yellow solution when hot and cold.

Sample E.-Formed a pale yellow solution when hot and in the cold.

Sample F.-Readily dissolved to a clear solution not changing in colour on cooling.

Sample G.-Slightly adherent. Dissolved readily to a pale yellow solution when hot. The solution on cooling was slightly opalescent.

Sample H.-A dry powder which caked up before dissolving, when it formed a clear solution when hot and in the cold.

Sample Y.-Readily dissolved to form a clear solution when hot and in the cold.

The writer was informed that samples " $E$ " and " $F$ " were commercial products and the other samples were laboratory preparations.

\section{Hydrogen-ion Concentrations of the Solutions of Sodium Hydnocarpate.}

The solutions prepared for injection were tested for $\mathrm{pH}$ by a Universal Indicator with unsatisfactory results and as no suitable apparatus was available at Bankura for the accurate determination of the $\mathrm{pH}$ of the solutions, Dr. Henry very kindly had these determined in his laboratory. Injections were proceeded with in the meantime.

A number of determinations were made confirming the difficulties McBain and $\mathrm{Hay}^{2}$ had found in the estimation of the $\mathrm{pH}$ of general soap solutions. The figures given below illustrate some of the difficulties found in this part of the subject.

The $\mathrm{pH}$ values adopted for use in the comparisons made are those found for a 3 per cent. aqueous solution of the sodium hydnocarpate sample containing 0.5 per cent. carbolic acid before sterilising, using a quinhydrone electrode and the apparatus of Brown and Broom $^{3}$. The variation in $\mathrm{pH}$ after sterilising the solution is negligible as will be seen from the table below. As the upper limit for the readings with a quinhydrone electrode is $8 \cdot 5$, the quinhydrone being affected at a higher alkalinity (see Brown and Broom), Dr. Henry also had a comparison of the $\mathrm{pH}$ made above this limit by the hydrogen electrode.

The $\mathrm{pH}$ determinations supplied by Dr. Henry are here tabulated. 
pH of Solutions of Sodium Hydnocarpate Fractions.

\begin{tabular}{|c|c|c|c|c|c|c|c|c|c|}
\hline \multirow[b]{2}{*}{ 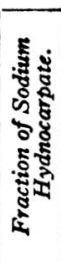 } & \multirow{2}{*}{ 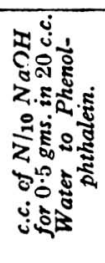 } & \multirow[b]{2}{*}{ 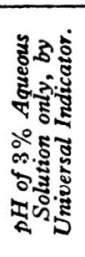 } & \multirow[b]{2}{*}{ 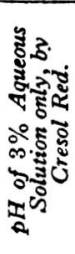 } & \multirow[b]{2}{*}{ 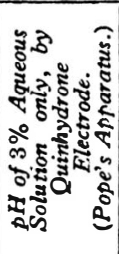 } & \multicolumn{3}{|c|}{$\begin{array}{l}\text { pH by Quinhydrone Elec- } \\
\text { trode (Brown and Broom's } \\
\text { Apparatus). }\end{array}$} & \multicolumn{2}{|c|}{$\begin{array}{c}\mathrm{pH} \text { by Hydrogen } \\
\text { Electrode. }\end{array}$} \\
\hline & & & & & 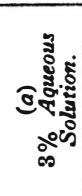 & 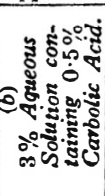 & 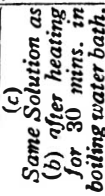 & 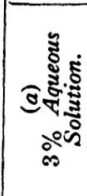 & 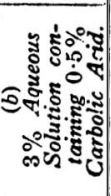 \\
\hline $\begin{array}{l}\text { A } \\
\text { B } \\
\text { C } \\
\text { D } \\
\text { E }\end{array}$ & $\begin{array}{l}0 \cdot 1 \\
0 \cdot 8 \\
1 \cdot 4 \\
0 \cdot 45 \\
0 \cdot 45\end{array}$ & $\begin{array}{l}8.0 \\
7.0 \\
6.5 \\
7.5 \\
8.5\end{array}$ & $\begin{array}{l}\overline{8 \cdot 6} \\
\overline{8 \cdot 3} \\
\overline{8 \cdot 7}\end{array}$ & $\begin{array}{l}8 \cdot 8 \\
8 \cdot 5 \\
8 \cdot 22 \\
9 \cdot 0 \\
8 \cdot 48\end{array}$ & $\begin{array}{l}9 \cdot 02 \\
8 \cdot 56 \\
8 \cdot 38 \\
9 \cdot 17 \\
9 \cdot 08\end{array}$ & $\begin{array}{l}8 \cdot 75 \\
8 \cdot 40 \\
8 \cdot 19 \\
8 \cdot 86 \\
8 \cdot 89\end{array}$ & $\begin{array}{l}8 \cdot 75 \\
8.43 \\
8 \cdot 14 \\
8 \cdot 87 \\
8 \cdot 84\end{array}$ & & \\
\hline $\begin{array}{l}\mathrm{F}^{*} \\
\mathbf{G} \\
\mathrm{H} \\
\mathrm{J}\end{array}$ & $\begin{array}{l}0.5 \\
1.3 \\
0 \cdot 8 \\
0 \cdot 15\end{array}$ & & & & $\begin{array}{l}9 \cdot 20 \\
8 \cdot 75 \\
9 \cdot 10 \\
9 \cdot 55\end{array}$ & $\begin{array}{l}8 \cdot 95 \\
8 \cdot 60 \\
8 \cdot 90 \\
9 \cdot 25\end{array}$ & & $\begin{array}{r}9 \cdot 44 \\
9 \cdot 03 \\
9 \cdot 14 \\
10 \cdot 38\end{array}$ & $\begin{array}{l}8 \cdot 94 \\
8 \cdot 68 \\
8 \cdot 89 \\
9 \cdot 38\end{array}$ \\
\hline
\end{tabular}

- Commercial products.

\section{Injections.}

For purposes of comparison, three series of patients were selected. Three sets of three such series were then arranged. In the first set of series, patients were selected who were previously receiving injections of "Alepol" by the subcutaneous method as their routine treatment. Details of these determinations are given in Table I.

A second set of series was afterwards arranged composed of patients previously receiving hydnocarpus wightiana oil, and oil of creosote (" hydnocreol ") as their routine treatment. The details of these are given in Table II.

Tables I and II comprise the observations made on the samples of sodium hydnocarpate marked A, B, C, D, E.

For the second batch of sodium hydnocarpate fractions $(F, G, H, J)$, a further set of three series was arranged. The patients for this set were selected without respect to previous routine treatment though such is recorded in the observations made on this set given in Table III.

Each series consisted of five patients for the first batch of samples and four patients for the second batch of samples, one for each solution. Injections were given to each patient twice a week, a course* consisting of six injections of 2,3 , $4,6,8$ and 10 c.c. Injections for each series were given at the same time using a fresh needle of the same size and bore for each patient. Each patient in the series received

- In ordinary routine the course from 2 to 10 c.c. would increase more gradually. 
the injection in the left arm on the first day of injection (say Monday), in the rightarm on the second day of injection (Thursday), then in the legs and afterwards in the thighs always in the same order and in such a way that the full course was given round the body in the same period, the larger volumes injected (8 and 10 c.c.) being given in the thighs.

The day following injection, each patient of the first series appeared for examination (see below) and a second series of five patients had their first injection.

The next day, the patients of Series I. and II. reported for observations and a third series of five patients received their first injection.

Injections were then proceeded with systematically as recorded in the Tables until each set of series had had the full course possible. By thus treating each series as a separate group on different days, one was able to avoid the psychological factor of a crowd of patients together influencing to some extent each other's report of individual symptoms.

In the selection of patients, the first series given in Tables I, II and III were all females. Series II and III in each case were males. Physique, general health and lack of extensive anæsthesia in injection sites were taken into consideration in the selection of patients for treatment. These factors, together with the approximate age of the patient, are recorded in each Table in columns 2 and 3.

The observations on each set of series were made after another set was completed so that the results given in each Table are independent of each other.

To avoid as far as possible the influence from varying climatic conditions, injections were made at the most stable seasons of the year when patients were not so liable to fall ill from malaria or other causes which would interfere with the course of treatment. The observations in Tables I and II were made in 1929, after the " rains." The period covered by Table I was from the end of August to about the end of September, and the period covered by Table II was from about the end of September to about the end of October. Table III covers the period of the month of June, 1930, which is the latter part of the hot, dry season in Bengal immediately before the " rains."

\section{Pain Factor.}

Observations of the signs and symptoms of the pain experienced by each patient were made in the early morning 
SOME OBSERVATIONS ON THE INFLUENCE C PAIN REACTION IN THE ADMINISTRATIO SUBCUTANEOL

TAB

(Patients accuston

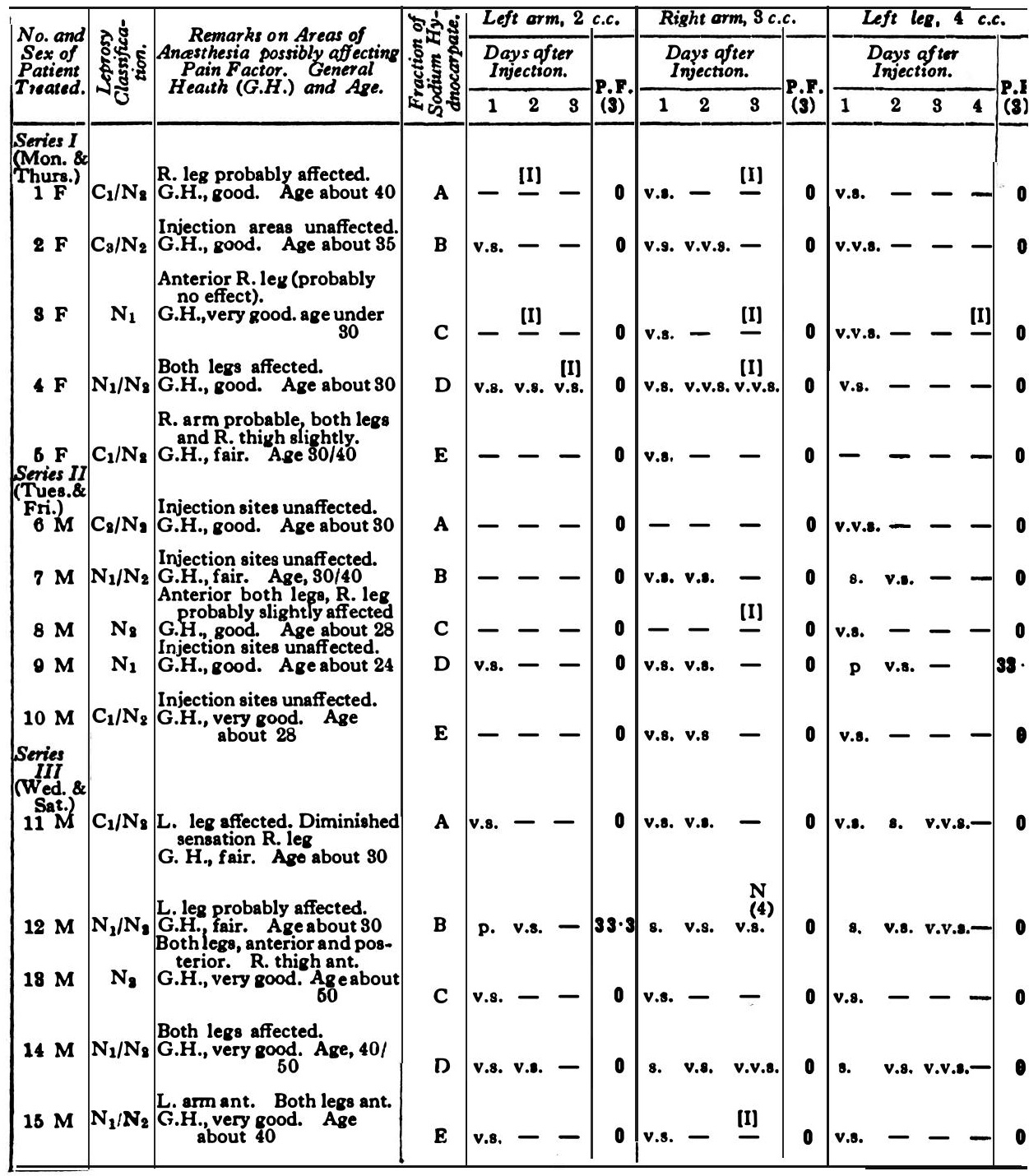

p =pain, m.p. -much pain, m.p.i. -much pain increasing, p.d. =pain decreasins, s.=slight pain, 
SOME OBSERVATIONS ON THE INFLUENCE PAIN REACTION IN THE ADMINISTRATIO SUBCUTANEOL

$\mathrm{TAB}$

(Patients accustom

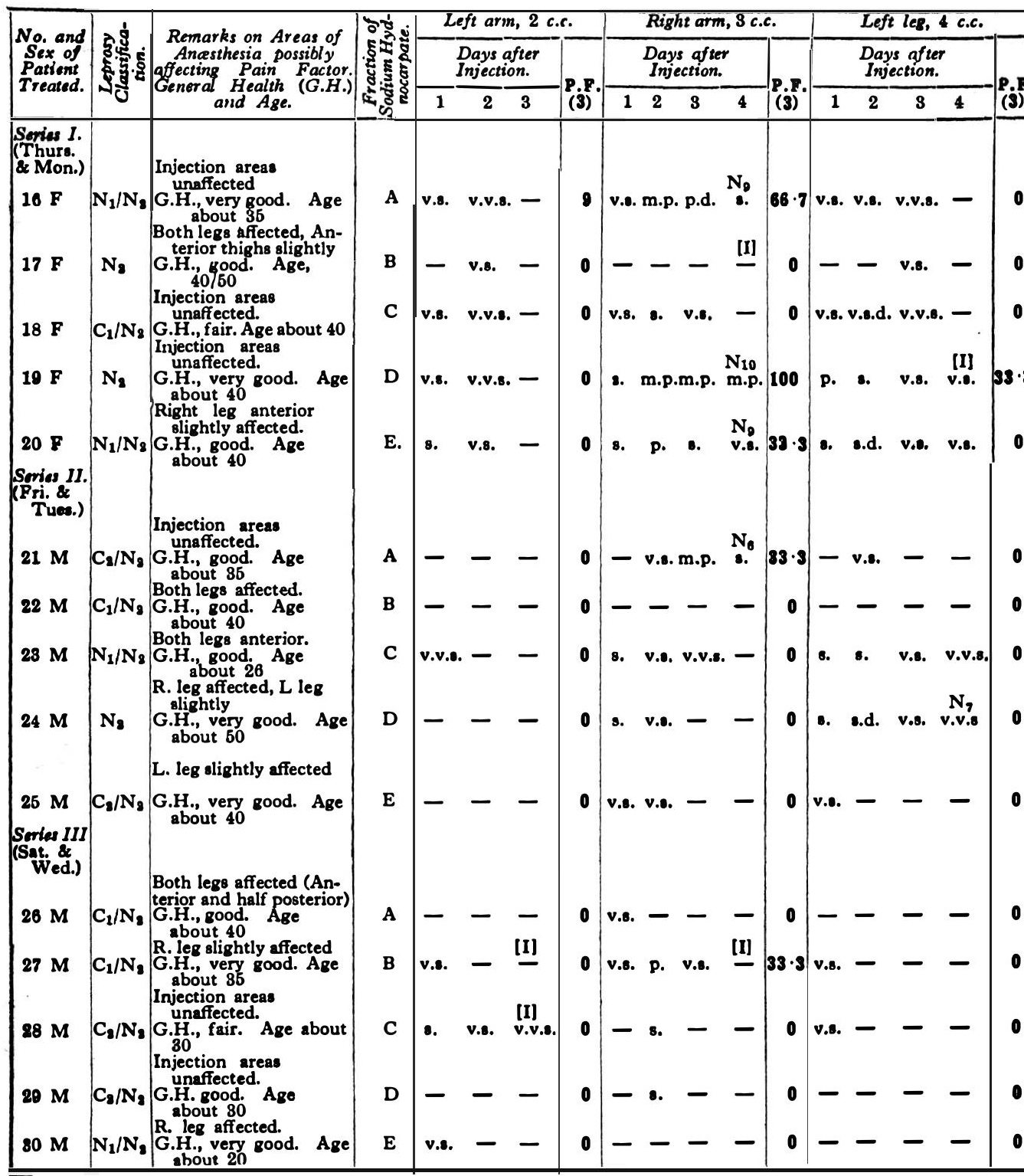


of each day before injections were given. A record was thus obtained for each 24-hour period following each injection until no further sensation at the site of the injection was experienced. These observations are recorded in the Tables under each injection and site of injection. What the author considered to be more than a normal sensation from an injection was recorded as "pain" (p) and anything less than this ignored in calculating the "P.F." as given below. By examining the patients consecutively each day apart from each other, the relative pain recorded was more or less constant. Induration was noted and if severe pain or fever developed during a course of injections, the course was stopped. It was generally found that if the general health of the patient fell much below normal, his pain reaction was more intense.

In order to collate the pain records for the injection courses for comparative purposes, a mathematical expression has been originated which the author has termed the "Pain Factor" denoted by the abbreviation "P.F." This value is arrived at as follows :-

For each particular injection, a normal period in days has been given as the time through which a normal sensation for that particular injection would disappear if unaccompanied by real pain. This period is given thus :- "P.F." (3), "P.F." (4), "P.F." (5), i.e., 3, 4 and 5 days the period is taken as the normal for these "Pain Factors" respectively for the particular volumes injected to which they apply. The normals thus adopted are (3) for injections of 2,3 and 4 c.c.; (4) for 6 and 8 c.c., and (5) for 10 c.c.

If only slight, gradually disappearing pain was observed for a particular injection, this was considered to be normal and the "P.F." for that injection recorded as zero. If real pain (recorded as " $p$ ") was observed on say two days during the period of sensation following an injection whose normal is given as (3), then the "P.F." for that particular injection period is given as

$$
\frac{2}{3} \times 100=66 \cdot 7
$$

so that the "P.F." for that injection is $66 \cdot 7$. Should pain (" $p$ ") have been observed on three days or more for the same injection on another patient, then the "P.F." for that patient for that particular injection would be 100 .

In such a manner a mathematical expression for the pain found has been recorded for each injection made. This value has been averaged for the injection courses 
(see Tables I, II and III) and then again averaged for the three series in each Table for the same fraction of sodium hydnocarpate (see Table IV). The "P.F." for each sample is then given as a final mean in Table IV. In this way, for the samples A, B, C, D, E, a mean "Pain Factor" has been determined from a course of injections over two different periods of about a month each and on six patients for each particular fraction of sodium hydnocarpate. The mean "P.F." for the fractions F, G, H, J, is based on one period of a month and for three patients for each sample. In this case, it was not practicable to carry on observations for a second period during the "rains" and the necessary time was not later available.

It will be realised that the "P.F." as a mathematical expression for each sample of sodium hydnocarpate, is not meant to carry any standard significance as a measurement of the pain value beyond being a measure which, to the mind of the author, is of use for relative purposes and for comparisons in the investigations here recorded. So far as the personal equation of the experimentalist is the same and other factors influencing the pain reaction can be kept common, then the "P.F." is a measure which appears valuable for comparative purposes.

The "P.F." for each fraction of sodium hydnocarpate examined with its corresponding $\mathrm{pH}$ is given in Table $\mathrm{V}$.

\section{Conclusions.}

An examination of Table $\mathrm{V}$ does not justify the conclusion of a definite relationship between the variations of $\mathrm{pH}$ and "P.F." over the limited range of $\mathrm{pH}$ examined. For example, the fractions of sodium hydnocarpate $\mathrm{C}, \mathrm{G}$ and $\mathrm{J}$, giving a $\mathrm{pH}$ for the solution injected of $8 \cdot 19,8 \cdot 60$ and 9.25 respectively, gave in each case the very low "P.F." of $3 \cdot 1,2 \cdot 8$ and $3 \cdot 3$ respectively. Thus, the samples having the lowest and highest alkalinity give equally good results so far as an exceedingly low pain reaction is concerned.

A high $\mathrm{pH}$ value, therefore, does not indicate a high "Pain Factor" other conditions being the same.

The writer regrets that he was unable to make a more extensive series of experiments with different strength solutions of the same products and also with further samples of sodium hydnocarpate prepared from the fatty acids from hydnocarpus oil whose "P.F." had also been determined. So far as he is aware, it has not yet been shown whether sodium hydnocarpate prepared from oils which 


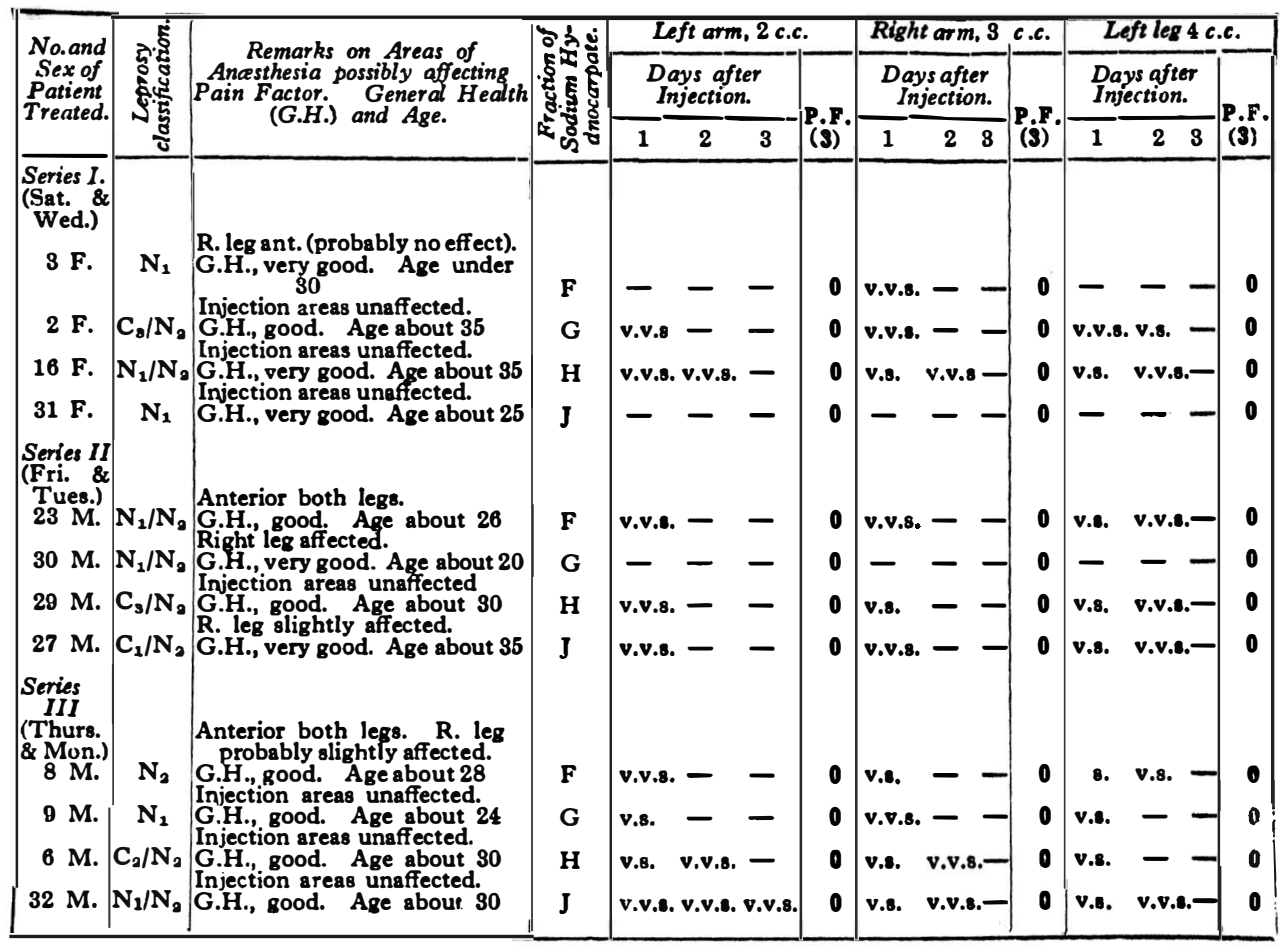

TABLE IV.

P.F. Averagrs.

\begin{tabular}{|c|c|c|c|c|c|c|c|c|c|}
\hline \multirow{2}{*}{ 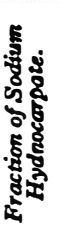 } & \multicolumn{4}{|c|}{ TABLE I. } & \multicolumn{4}{|c|}{ TABLB II. } & \multirow[b]{2}{*}{$\begin{array}{l}\text { Wnal } \\
\text { P.togn. } \\
\text { P.f. }\end{array}$} \\
\hline & $\begin{array}{c}\text { Series } \\
\text { I. } \\
\text { P.F. }\end{array}$ & $\begin{array}{c}\text { Series } \\
I I . F . \\
P . F .\end{array}$ & $\begin{array}{c}\text { Series } \\
\text { III. } \\
\text { P.F. }\end{array}$ & $\begin{array}{l}\text { Average } \\
\text { P.F. for } \\
\text { 3 cortios of } \\
\text { Infootion } \\
\text { Courses. }\end{array}$ & $\begin{array}{c}\text { Seriles } \\
I . \\
P . F .\end{array}$ & $\begin{array}{c}\text { Series } \\
\boldsymbol{H} . \dot{F} \\
\boldsymbol{P} . \dot{F}\end{array}$ & $\begin{array}{c}\text { Serles } \\
\text { III. } \\
P . F .\end{array}$ & $\begin{array}{c}\text { Average } \\
\text { P.F. Ior } \\
\text { 3 soriog of } \\
\text { Infoetton } \\
\text { Courses. }\end{array}$ & \\
\hline \multirow[t]{2}{*}{$\begin{array}{l}\mathbf{A} \\
\mathbf{B} \\
\mathbf{C} \\
\mathbf{D} \\
\mathbf{E}\end{array}$} & $\begin{array}{c}0 \\
3 \cdot 3 \\
0 \\
15 \cdot 0 \\
6 \cdot 7 \\
\end{array}$ & $\begin{array}{c}11 \cdot 7 \\
15 \cdot 0 \\
0 \\
26 \cdot 7 \\
18 \cdot 3 \\
\end{array}$ & $\begin{array}{c}\overline{36 \cdot 7} \\
0 \\
30 \cdot 0 \\
10 \cdot 0 \\
\end{array}$ & $\begin{array}{c}5.9 \\
18.8 \\
0 \\
28.9 \\
11.7 \\
\end{array}$ & $\begin{array}{c}26 \cdot 1 \\
6 \cdot 7 \\
0 \\
34 \cdot 7 \\
16 \cdot 4\end{array}$ & $\begin{array}{r}24 \cdot 7 \\
6 \cdot 7 \\
18 \cdot 3 \\
16 \cdot 7 \\
18 \cdot 3\end{array}$ & $\begin{array}{c}11 \cdot 7 \\
26 \cdot 7 \\
0 \\
16 \cdot 7 \\
3 \cdot 3\end{array}$ & $\begin{array}{r}20.8 \\
18.4 \\
6 \cdot 1 \\
22.7 \\
12.7\end{array}$ & $\begin{array}{r}18 \cdot 4 \\
15 \cdot 9 \\
8.1 \\
28.8 \\
12 \cdot 8\end{array}$ \\
\hline & \multicolumn{4}{|c|}{ TABLE III. } & & & & & \\
\hline $\begin{array}{l}\mathbf{F} \\
\mathbf{G} \\
\mathbf{H} \\
\mathbf{J}\end{array}$ & $\begin{array}{c}0 \\
0 \\
15 \cdot 8 \\
0\end{array}$ & $\begin{array}{c}23 \cdot 3 \\
0 \\
6 \cdot 7 \\
0\end{array}$ & $\begin{array}{c}0 \\
8 \cdot 3 \\
15 \cdot 8 \\
10 \cdot 0\end{array}$ & $\begin{array}{r}7.8 \\
2.8 \\
12.8 \\
8.8\end{array}$ & & & & & $\begin{array}{r}7.8 \\
8.8 \\
18.8 \\
8.8\end{array}$ \\
\hline
\end{tabular}


II.

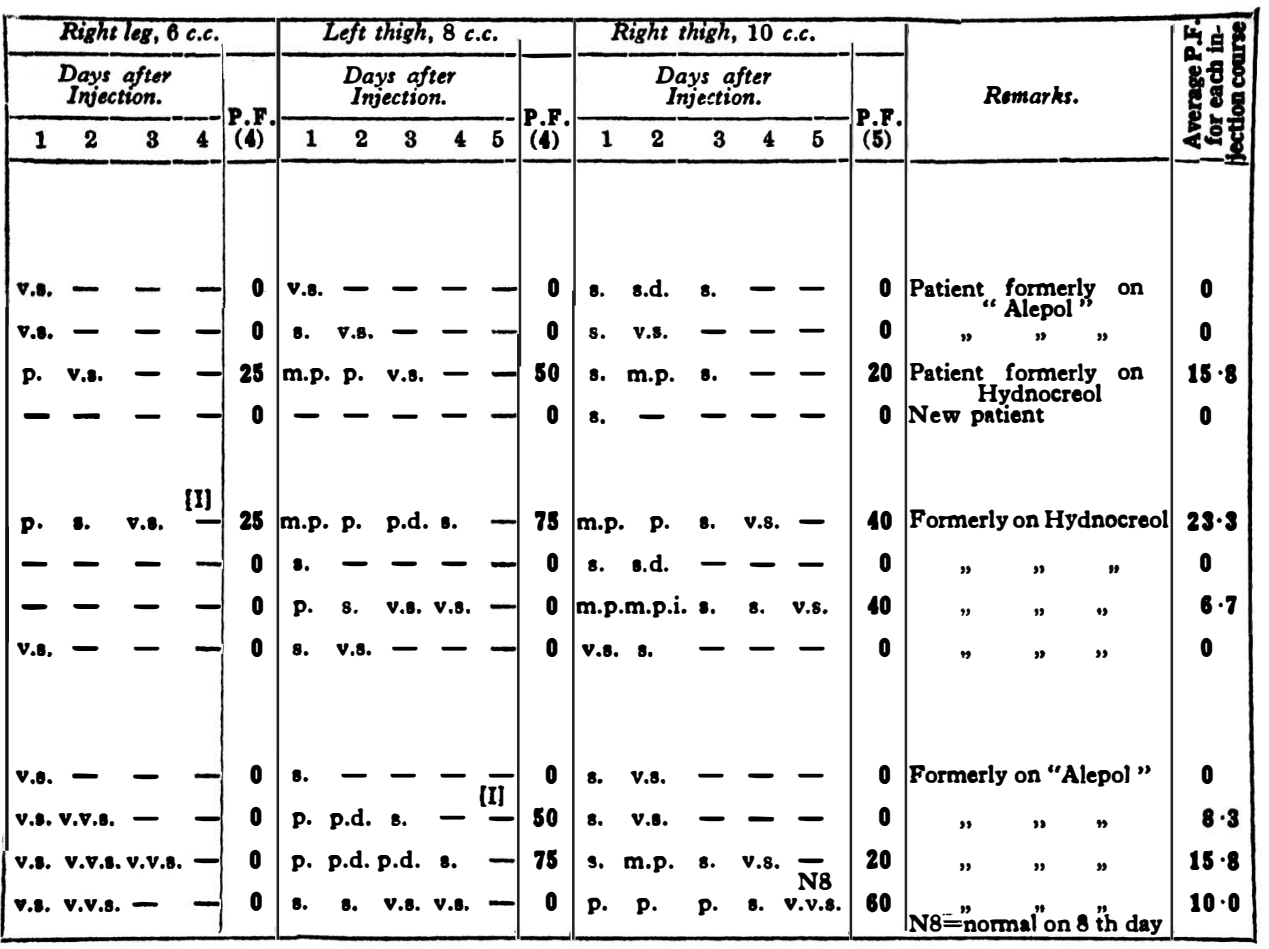

TABLE V.

Showing Relation of P.F. to Hydrogen-ion Concentration.

\begin{tabular}{|c|c|c|c|c|c|}
\hline 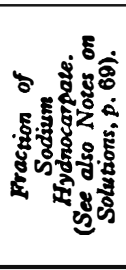 & 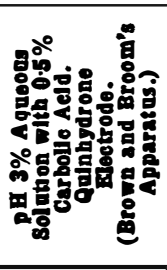 & 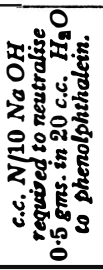 & 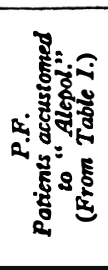 & 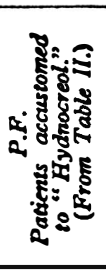 & 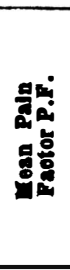 \\
\hline $\begin{array}{l}\text { C } \\
\mathbf{B} \\
\mathbf{G} \\
\mathbf{A} \\
\mathbf{D} \\
\mathbf{E}^{*} \\
\mathbf{H} \\
\mathbf{F}^{*} \\
\text { J }\end{array}$ & $\begin{array}{l}8 \cdot 19 \\
8 \cdot 40 \\
8 \cdot 60 \\
8 \cdot 75 \\
8 \cdot 86 \\
8 \cdot 89 \\
8 \cdot 90 \\
8 \cdot 95 \\
8 \cdot 25\end{array}$ & $\begin{array}{l}1 \cdot 4 \\
0.8 \\
1 \cdot 3 \\
0.1 \\
0.45 \\
0.45 \\
0.8 \\
0.5 \\
0.15\end{array}$ & $\begin{array}{c}0 \\
18 \cdot 3 \\
5 \cdot 9 \dagger \\
23 \cdot 9 \\
11 \cdot 7\end{array}$ & $\begin{array}{r}6 \cdot 1 \\
13 \cdot 4 \\
\\
20 \cdot 8 \\
22 \cdot 7 \\
12 \cdot 7\end{array}$ & $\begin{array}{r}8.1 \\
15 \cdot 9 \\
2.8 \\
18.4 \\
28.8 \\
12.2 \\
12.8 \\
7 \cdot 8 \\
8.8\end{array}$ \\
\hline
\end{tabular}

- Commercial products. + From two series only.

N.B.-Samples A, B, C, D, E are prepared from the same fraction $\mathrm{X}$ of the fatty acids from Hydnocarpus Oil. Samples F, G, H, J are further samples separately prepared. 
give much pain in treatment, also give pain themselves on injection.

The commercial products tested ( $\mathrm{E}$ and $\mathrm{F}$ ) give a comparatively low pain reaction, $\mathrm{F}$ being the better product from this standpoint.

The samples $\mathrm{C}$ and $\mathrm{G}$ which gave slight precipitation and opalescence in solution respectively, gave a very low pain reaction $(3 \cdot 1$ and $2 \cdot 8$ respectively). Such slight precipitation and opalescence in the solution, when due to chemical and not biological reasons, does not, therefore, indicate that there will be excessive pain.

Comparative experiments on the addition of glycerine to sodium hydnocarpate solutions to reduce the pain reaction have been made and will be communicated in a following paper.

The author desires to thank Dr. R. G. Cochrane who made this investigation possible and also Dr. T. A. Henry for so kindly supplying the preparations of sodium hydnocarpate and determining their $\mathrm{pH}$ values.

$\mathrm{He}$ would also specially like to express his thanks to all his friends without whose cheerful and willing co-operation as patients, these tests could not have been carried out.

\section{REFERENCES.}

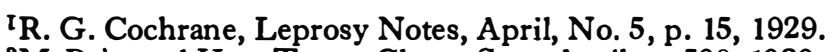

${ }^{2}$ McBain and Hay, Trans. Chem. Soc., April, p. 590, 1929.

3Brown and Broom, Trans. Roy. Soc. Trop. Med. \& Hyg. Vol. zxiii, No. 2, pp. 155-160, 1929. 